\title{
Short communication: The effect of temperature-humidity index on milk yield and milking frequency of dairy cows in pasture-based automatic milking systems
}

\author{
Ashleigh M. Wildridge, ${ }^{* 1}$ Peter C. Thomson, $†$ Sergio C. Garcia, ${ }^{*}$ Alex J. John, ${ }^{*}$ Ellen C. Jongman,ł \\ Cameron E. F. Clark, ${ }^{*}$ and Kendra L. Kerrisk* \\ *Dairy Science Group, \\ †School of Life and Environmental Sciences, Faculty of Science, The University of Sydney, Camden, NSW 2570, Australia \\ $\ddagger$ Animal Welfare Science Centre, Faculty of Veterinary and Agricultural Sciences, The University of Melbourne, Parkville, VIC 3010, Australia
}

\begin{abstract}
Hot weather is known to negatively affect cow performance primarily through reduced feed intake and milk yield. However, little information is available on how it affects cow milk yield and milking frequency in automatic milking systems (AMS). Milking data were collected from 6 pasture-based AMS farms in Australia to assess the effect of temperature-humidity index (THI) on milk yield and milking frequency. Daily measures of average milk yield per cow and average milking frequency per cow during December to February (Australian summer) were assessed for associations with maximum, minimum, and average THI from d 0 , $-1,-2$, and -3 in relation to the milking data. Average daily milk yield per cow was negatively associated with an increasing maximum, minimum, and average THI $(-0.11,-0.08$, and $-0.15 \mathrm{~kg} / \mathrm{THI}$ unit increase, respectively) on the collection day and up to $3 \mathrm{~d}$ prior. The average daily milking frequency was negatively associated with maximum THI on $1 \mathrm{~d}(-0.003 / \mathrm{THI}$ unit increase) and $2 \mathrm{~d}$ (-0.003/THI unit increase) before collection. Our results show that high THI conditions were negatively associated with milking frequency and milk yield in a pasture-based AMS and that research into management and infrastructure (cow cooling) in these systems is warranted to reduce production losses. Key words: heat stress, summer, voluntary traffic
\end{abstract}

\section{Short Communication}

Hot weather conditions are associated with reductions in dairy cow feed intake and milk yield (Garner et al., 2017). Compounding this effect, selection of cows for improved genetic potential for production

Received September 20, 2017.

Accepted January 23, 2018.

${ }^{1}$ Corresponding author: ashleigh.wildridge@syndey.edu.au has also reduced heat tolerance of dairy cows (Ravagnolo and Misztal, 2000). In this regard, the average temperature-humidity index (THI) threshold for reduced milk production was 72 (approximately $25^{\circ} \mathrm{C}$ at 50\% relative humidity; Igono et al., 1992); $10 \mathrm{yr}$ later, research by Bouraoui et al. (2002) found that the threshold had decreased to 68 (approximately $22^{\circ} \mathrm{C}$ at $50 \%$ relative humidity). In an indoor automatic milking system (AMS) where cows voluntarily traffic to the milking facility, greater milk yield reductions have been reported compared with cows that were batch milked in an indoor system. This trend was seen when THI exceeded 72 and the AMS cows volunteered for milking less frequently (Speroni et al., 2006). Due to the negative effect of hot weather on cow activity and performance (West, 2003a) and the greater traveling distances required by pasture-kept cows, the effect of THI on milk yield and milking frequency in a pasturebased AMS is predicted to be greater and needs to be quantified. To do this, we used milking and weather data from commercial pasture-based AMS farms to investigate the effect of THI on milking frequency and milk yield during summer. It was hypothesized that milking frequency would be negatively affected by high THI conditions on the same day and that milk yield would be negatively associated with a greater THI on previous days.

Farms that had been operating for a minimum of 2 yr and were pasture based within Victoria, Tasmania, New South Wales, and South Australia were contacted to participate in the study. We contacted 15 out of 19 eligible farms, with 6 farms accepting to take part in the study and have data captured from their AMS support software during 2015. At the time of data collection, the farms were operating with voluntary cow traffic and offered either 2 or 3 pasture allocations per day to encourage voluntary cow traffic. The farms ranged in size from 120 to 575 lactating dairy cows milked by $4 \pm 2$ single-box AMS (various brands) or a 24-bail 
automatic milking rotary (DeLaval, Tumba, Sweden). We downloaded the maximum available history (6 mo to $4 \mathrm{yr}$ ) of individual cow milking records from the support software on each AMS farm. This information included cow identification, date and time of individual milking sessions, and the total milk yield $(\mathrm{kg})$ from that given session. Human ethics approval to access the data was granted through the University of Sydney (approval code US, 2014/737). Animal ethics approval was not required because the study was based entirely on historical data with no intervention at the animal or herd levels.

We obtained weather data from the Australian $\mathrm{Bu}-$ reau of Meteorology (2016), from the weather station geographically closest $(12-49 \mathrm{~km})$ to each of the farms. Due to the distance of the weather stations from the farms, the THI values used in this study may have differed from the actual on-farm conditions and this is a limitation of the study. In addition, 2 farms used weather data from the same weather station, which was located approximately $12 \mathrm{~km}$ from one farm and 19 $\mathrm{km}$ from the other. Those farms were located approximately $7.5 \mathrm{~km}$ from each other, where the farthest 2 farms were approximately $700 \mathrm{~km}$ apart.

The weather information included hourly records of temperature $\left({ }^{\circ} \mathrm{C}\right)$ and relative humidity $(\%)$. The temperature and relative humidity records were used to calculate hourly THI in Microsoft Excel (Microsoft Corp., Redmond, WA) using the following formula (Kelly and Bond, 1971):

$$
\begin{aligned}
\mathrm{THI}=(1.8 \times & \mathrm{T}+32)-(0.55-0.0055 \times \mathrm{RH}) \\
& \times(1.8 \times \mathrm{T}-26),
\end{aligned}
$$

where $\mathrm{T}=$ temperature $\left({ }^{\circ} \mathrm{C}\right)$ and $\mathrm{RH}=$ relative humidity $(\%)$.

The weather data were used to calculate 12 THIrelated variables, including maximum, minimum, and average daily THI from $\mathrm{d} 0,-1,-2$, and -3 relative to the milking data. The milking records from all farms during the summer months of December to February were extracted. The summer periods of 2012 to 2013 and 2013 to 2014 contained data from 3 farms totaling 270 and $268 \mathrm{~d}$ of milking data, respectively, and the summer period of 2014 to 2015 contained $503 \mathrm{~d}$ of milking data from 6 farms. Only data from summer were included to maximize the occurrence of days with a high THI and to avoid the confounding effect of stage of lactation, as most farms calved seasonally. The overall average THI was $61.6 \pm 4.5$ with an average milk yield of $22.3 \pm 5.6 \mathrm{~kg} / \mathrm{cow}$ and a milking frequency of $2.3 \pm 0.3$. Approximately $10 \%$ of the milking records were associated with an average THI of 68 or greater, with an average milk yield of $19.1 \pm 5.7 \mathrm{~kg} / \mathrm{cow}$ and a milking frequency of $2.2 \pm 0.3$. Approximately $50 \%$ of records were associated with a maximum THI of 68 or greater, with an average milk yield of $21.2 \pm 5.6 \mathrm{~kg} /$ cow and a milking frequency of $2.3 \pm 0.3$.

Average milk yield per cow per day and the average milking frequency per cow per day for each farm were calculated using Microsoft Excel. We used Genstat (16th edition; VSN International, Hemel Hempstead, UK) to perform a linear mixed model analysis (fitted using a REML procedure) on the data. The average milk yield per cow per day and milking frequency per cow per day were the outcome variables, each THI variable was fitted as a fixed effect (covariate), and farm was the random effect. Only univariable models were considered due to correlations among the 12 predictor variables and the difficulties in interpreting regression coefficients from multivariable models in these situations.

We found an association between all THI variables $(P$ $<0.001$ ) and the milk yield per cow per day (Table 1 ). The average THI had the greatest effect on milk yield (average $0.15-\mathrm{kg}$ decline for every THI unit increase) over all test days (d $0,-1,-2$, and -3 ), followed by maximum THI (average $0.11-\mathrm{kg}$ decline) and then minimum THI (average $0.08-\mathrm{kg}$ decline), where day -3 had the lowest effect overall. The average milking frequency per cow per day was negatively associated with maximum THI on $\mathrm{d}-1$ and maximum THI on $\mathrm{d}$ $-2(P<0.05)$, where average THI on $\mathrm{d}-1$ and average THI on $\mathrm{d}-2$ approached significance $(0.05<P<0.1)$.

The findings of this study support the hypothesis that high THI conditions from up to 3 previous days have a negative effect on milk yield, in line with the findings by Bouraoui et al. (2002). Specifically, the average THI conditions on $\mathrm{d} 0,-1$, and -2 in the current study were associated with greater reductions in milk yield compared with $\mathrm{d}-3$ and the maximum and minimum THI of all days. Previous research has also reported average air temperature (West et al., 2003b) and maximum temperature (Wagner-Storch and Palmer, 2003) of up to $2 \mathrm{~d}$ before to be linked with milk yield variation. The average THI had the greatest effect on milk yield compared with the maximum and minimum THI across all days $(0,-1,-2$, and -3$)$. This finding differs slightly from the findings of West et al. (2003b), who identified $d-2$ as having the greatest influence on milk yield. The magnitude of the milk yield reductions also differed, where every unit increase in THI resulted in a $0.15-\mathrm{kg}$ decline in milk yield in the current study but a 0.88-kg decline in West et al. (2003b). This difference may be attributed to the normally lower production (and therefore lower susceptibility to heat stress; Collier et al., 2006) of pasture-based cows compared with 
Table 1. Regression coefficients for the effect of temperature-humidity index (THI) variables (maximum, minimum, and average) from $\mathrm{d} 0,-1,-2$, and -3 in relation to the milking data on the average daily milk yield and milking frequency per cow

\begin{tabular}{|c|c|c|c|c|c|c|c|}
\hline \multirow[b]{2}{*}{ Day } & \multirow[b]{2}{*}{ THI variable } & \multicolumn{3}{|c|}{ Milk yield } & \multicolumn{3}{|c|}{ Milking frequency } \\
\hline & & $\mathrm{RC}^{1}$ & $\mathrm{SE}$ & $P$-value & $\mathrm{RC}$ & $\mathrm{SE}$ & $P$-value \\
\hline \multirow[t]{3}{*}{0} & Maximum & -0.11 & 0.015 & $<0.001$ & -0.001 & 0.001 & 0.22 \\
\hline & Minimum & -0.09 & 0.013 & $<0.001$ & -0.000 & 0.001 & 0.94 \\
\hline & Average & -0.15 & 0.018 & $<0.001$ & -0.002 & 0.001 & 0.17 \\
\hline \multirow[t]{3}{*}{-1} & Maximum & -0.12 & 0.015 & $<0.001$ & -0.003 & 0.001 & 0.01 \\
\hline & Minimum & -0.08 & 0.013 & $<0.001$ & 0.001 & 0.001 & 0.57 \\
\hline & Average & -0.15 & 0.018 & $<0.001$ & -0.003 & 0.001 & 0.06 \\
\hline \multirow[t]{3}{*}{-2} & Maximum & -0.11 & 0.014 & $<0.001$ & -0.003 & 0.001 & 0.01 \\
\hline & Minimum & -0.08 & 0.013 & $<0.001$ & 0.000 & 0.001 & 0.89 \\
\hline & Average & -0.15 & 0.018 & $<0.001$ & -0.002 & 0.001 & 0.08 \\
\hline \multirow[t]{3}{*}{-3} & Maximum & -0.10 & 0.015 & $<0.001$ & -0.001 & 0.001 & 0.63 \\
\hline & Minimum & -0.08 & 0.013 & $<0.001$ & 0.001 & 0.001 & 0.46 \\
\hline & Average & -0.14 & 0.018 & $<0.001$ & -0.001 & 0.001 & 0.66 \\
\hline
\end{tabular}

${ }^{1}$ Regression coefficient.

indoor cows in addition to the current study having lower overall average THI conditions $(61.6 \pm 4.5$, mean $\pm \mathrm{SD})$ compared with West et al. (2003b; $77.9 \pm 2.5$, mean $\pm \mathrm{SD})$. Higher THI conditions, particularly overnight, would have further increased the heat burden on the cows, thereby increasing the negative effects of heat stress on production. To reduce the effect of high THI on dairy cows in conventional milking systems (CMS), the use of shade (Palacio et al., 2015), sprinklers (Kendall et al., 2007), fans, and misters (Collier et al., 2006) has been successfully implemented. Implementing cow cooling strategies in a CMS when cows are managed as a herd has a minimal risk of creating congestion within the system as cows are fetched manually when required (i.e., for milking). In an AMS operating with voluntary cow traffic, providing cow cooling requires more consideration as it can cause congestion, as found in our previous study, where the provision of shade in the premilking area of a pasture-based AMS increased the voluntary waiting time of cows for milking (Wildridge et al., 2017).

It was hypothesized that the milking frequency of cows would decrease in response to high THI conditions within the same day; however, we found maximum THI on $\mathrm{d}-1$ and maximum THI on $\mathrm{d}-2$ to be negatively associated with milking frequency. This finding is in line with Speroni et al. (2006), who showed that cows had a lower milking frequency during the spring-summer period than during the autumn-winter period. Speroni et al. (2006) also noted that the milk yield of cows in an indoor AMS (with reduced milking frequency) had declined more rapidly than the milk yield of a herd that was simultaneously batch milked in an indoor CMS. Stelwagen (2001) also reported a reduced milk yield with less frequent milking, supporting the findings of the current study, where the milk yield and milking frequency of cows were most affected by high THI conditions on $\mathrm{d}-1$ and -2 . Considering this, increased fetching of cows to encourage additional milkings before and after particularly hot weather may be useful to potentially reduce the expected decline in milking frequency and, to some extent, the reductions in milk yield (Stockdale, 2006). The milk yield of cows may also be further improved by providing shade to the cows in the premilking area of the milking facility (Wildridge et al., 2017).

During hot weather, cows are often less active (West, 2003a) as their body temperature increases in response to locomotion (Schütz et al., 2011). This indicates a reduced motivation for traveling to the milking facility; therefore, a decline in milking frequency during and soon after (overnight) a heat event would be predicted. Considering the common behavioral adaptations of cows during hot weather, it was surprising that THI conditions on the testing day did not significantly affect milking frequency. Results instead show that a lag effect exists of 1 to $2 \mathrm{~d}$ between high THI conditions and reduced milking frequency in pasture-based AMS. This may also be somewhat affected by the nature of the data, whereby a cow may have presented for their final milking on a given day before the maximum THI, therefore affecting the association of THI with milking frequency on a given day.

We have shown that increasing THI conditions from up to $3 \mathrm{~d}$ previous was negatively associated with milk yield, whereas an increasing maximum THI on $\mathrm{d}-1$ and -2 was negatively associated with milking frequency for cows in pasture-based AMS during summer. This finding supports the consideration of farm management and infrastructure (cow cooling) modifications in future research to reduce the effect of a high THI on cow milk yield and milking frequency in pasture-based AMS. 


\section{ACKNOWLEDGMENTS}

We acknowledge The University of Sydney (Australia) and the FutureDairy project for providing the funding for this research. We also thank the 6 farmers who participated in the study.

\section{REFERENCES}

Australian Bureau of Meteorology. 2016. Historical weather data. Accessed Aug. 10, 2016. http://www.bom.gov.au/climate/data -services/data-requests.shtml.

Bouraoui, R., M. Lahmar, A. Majdoub, M. Djemali, and R. Belyea. 2002. The relationship of temperature-humidity index with milk production of dairy cows in a Mediterranean climate. Anim. Res. 51:479-491.

Collier, R. J., G. E. Dahl, and M. J. VanBaale. 2006. Major advances associated with environmental effects on dairy cattle. J. Dairy Sci. $89: 1244-1253$

Garner, J. B., M. Douglas, S. R. O. Williams, W. J. Wales, L. C. Marett, K. DiGiacomo, B. J. Leury, and B. J. Hayes. 2017. Responses of dairy cows to short-term heat stress in controlled-climate chambers. Anim. Prod. Sci. 57:1233-1241.

Igono, M. O., G. Bjotvedt, and H. T. Sanford-Crane. 1992. Environmental profile and critical temperature effects on milk production of Holstein cows in desert climate. Int. J. Biometeorol. 36:77-87.

Kelly, C. F., and T. E. Bond. 1971. Bioclimatic Factors and Their Measurement: A Guide to Environmental Research on Animals. National Academy Press, Washington, DC.
Kendall, P. E., G. A. Verkerk, J. R. Webster, and C. B. Tucker. 2007. Sprinklers and shade cool cows and reduce insect-avoidance behavior in pasture-based dairy systems. J. Dairy Sci. 90:3671-3680.

Palacio, S., R. Bergeron, S. Lachance, and E. Vasseur. 2015. The effects of providing portable shade at pasture on dairy cow behavior and physiology. J. Dairy Sci. 98:6085-6093.

Ravagnolo, O., and I. Misztal. 2000. Genetic component of heat stress in dairy cattle, parameter estimation. J. Dairy Sci. 83:2126-2130.

Schütz, K. E., A. R. Rogers, N. R. Cox, J. R. Webster, and C. B Tucker. 2011. Dairy cattle prefer shade over sprinklers: Effects on behavior and physiology. J. Dairy Sci. 94:273-283.

Speroni, M., G. Pirlo, and S. Lolli. 2006. Effect of automatic milking systems on milk yield in a hot environment. J. Dairy Sci 89:4687-4693.

Stelwagen, K. 2001. Effect of milking frequency on mammary functioning and shape of the lactation curve. J. Dairy Sci. 84:E204-E211.

Stockdale, C. R. 2006. Influence of milking frequency on the productivity of dairy cows. Aust. J. Exp. Agric. 46:965-974.

Wagner-Storch, A. M., and R. W. Palmer. 2003. Feeding behavior, milking behavior, and milk yields of cows milked in a parlor versus an automatic milking system. J. Dairy Sci. 86:1494-1502.

West, J. W. 2003a. Effects of heat-stress on production in dairy cattle. J. Dairy Sci. 86:2131-2144.

West, J. W., B. G. Mullinix, and J. K. Bernard. 2003b. Effects of hot, humid weather on milk temperature, dry matter intake, and milk yield of lactating dairy cows. J. Dairy Sci. 86:232-242.

Wildridge, A. M., S. C. Garcia, P. C. Thomson, E. C. Jongman, C. E. F. Clark, and K. L. Kerrisk. 2017. The impact of a shaded premilking yard on a pasture-based automatic milking system. Anim. Prod. Sci. 57:1219-1225. 